\title{
Text-Based BIPA Teaching in Industrial Revolution Era 4.0
}

\author{
Vismaia S. Damaianti ${ }^{1}$, Yeti Mulyati ${ }^{2}$, Andoyo Sastromiharjo ${ }^{3}$, Suci Sundusiah ${ }^{4}$ \\ ${ }^{1234}$ Indonesia University of Education, Indonesia \\ 1vismaia@upi.edu, 22yetimulyati@upi.edu, 3andoyo@upi.edu , \\ ${ }^{4}$ suci.sundusiah@upi.edu
}

\begin{abstract}
This article is a text-based BIPA (Indonesian for Foreigner Learner) teaching idea in the industrial revolution era 4.0. Teaching BIPA in the era of the industrial revolution 4.0 presents its own challenges for teachers and learners. Texts in the industrial revolution era circulated in various modes, not only language modes, but also visual and audio modes based on big data. Teaching BIPA text-based material in 4.0 era means making text 4.0 as a means of mastering the learner's language competence. Stages of BIPA teaching model based on text 4.0 are (1) building the context of the text; (2) deconstructing the context of the text; (3) gradually training students; and (4) independent performance. To balance out the competence in using technological sophistication, BIPA teachers must still have basic skills in mastering (1) SKL (graduate competence standard) BIPA learning that can refer to the contents of Permedikbud Num. 27/2017; (2) basic principles of BIPA learning; (3) Indonesian language discipline content; (3) various teaching methodologies, especially for teaching foreign languages or second languages; andragogy teaching concepts; and the concepts of teaching planning, implementation and evaluation.
\end{abstract}

Keywords: Teaching BIPA (Indonesian for Foreigner Learner) BIPA in 4.0 era, language content of Teaching BIPA, SKL (graduate competence standard)

\section{PENDAHULUAN}

Istilah "revolusi industri 4.0" pertama kali dicetuskan oleh pemerintah Jerman pada tahun 2013 sebagai strategi rencana industri penelitian sains. Proyek ini menjadi pionir industri Teknologi Informasi (TI). Setelah revolusi industri 1.0, 2.0, dan 3.0 menghasilkan mekanisasi, produksi massal, dan digitalisasi melalui pengenalan mesin uap, elektronik dan teknologi informasi, revolusi industri 4.0 menghasilkan perpaduan dunia digital dan fisik melalui kemajuan teknologi, seperti layanan internet [1].

Kemajuan teknologi di era 4.0 ini mempengaruhi perubahan tatanan pendidikan dan pembelajaran [2], baik dalam pembelajaran bahasa secara umum [3] maupun dalam pembelajaran BIPA [4]. Pemelajar BIPA dari berbagai negara dapat mengakses dan melakukan pembelajaran mandiri melalui berbagai situs di internet yang diunggah oleh berbagai kalangan. Terbukanya arus informasi melalui internet ini juga dapat dijadikan sumber belajar dan media pengajaran bagi pengajar BIPA. Namun demikian, kontrol terhadap konten sumber belajar di media internet harus dilakukan oleh para pengajar dan pegiat BIPA, karena tidak semua konten 
internet layak dijadikan sumber belajar. Dengan demikian, era revolusi industri 4.0 memberikan tantangan serta peluang yang besar bagi pembelajaran BIPA. Tantangan bagi pengajar BIPA selayaknya menjadi peluang untuk meningkatkan kompetensi diri dalam mengajar, terutama dalam memilih dan menentukan sumber belajar serta media pembelajaran.

Tantangan kemajuan teknologi di era revolusi industri adalah latar perkembangan sosial dan teknologi yang akan terus berkembang. Akan tetapi, karakter dasar pengajar BIPA yang memiliki bekal kompetensi dalam menghadapi segala tantangan dan peluang tersebut tidak berubah. Beberapa karakter dasar yang menjadi bekal kompetensi pengajar BIPA adalah (1) penguasaan terhadap kurikulum BIPA; (2) penguasaan terhadap konsep dan konten "kompetensi berbahasa" dan "kompetensi bahasa"; (3) penguasaan terhadap konsep "learning" dan "acquisition"; (4) penguasaan terhadap berbagai pendekatan, metode, teknik, model, dan strategi pengajaran BIPA baik umum maupun khusus; (5) penguasaan terhadap konsep pembelajaran andragogi dan pembelajaran fungsional; (6) penguasaan terhadap konsep perencanaan, pelaksanaan, dan evaluasi dalam proses belajar mengajar BIPA.

\section{METODE PENELITIAN}

Tulisan ini bermaksud menyampaikan gagasan pelatihan untuk calon pengajar BIPA dengan konten materi kebahasaan berbasis teks di era revolusi industri 4.0. Hal-hal yang akan dibahas meliputi : (1) teks dalam pengajaran BIPA di era revolusi industri 4.0; (2) materi kebahasaan dalam pengajaran BIPA berbasis teks; (3) skema model pelatihan BIPA materi kebahasaan berbasis teks.

\section{HASIL DAN PEMBAHASAN}

\subsection{Teks dalam Pembelajaran BIPA di Era Revolusi Industri 4.0}

Teks merupakan satu kesatuan bahasa yang lengkap secara sosial dan kontekstual. Teks berfungsi secara sosial menyampaikan makna yang terkadung di dalam konteks. Teks menyampaikan proses sosial antara pembaca dan penulisnya. Sebagaimana yang dinyatakan Halliday secara fungsional, teks berupa bahasa digunakan untuk mengekspresikan suatu tujuan atau fungsi proses sosial di dalam konteks situasi dan konteks kultural [5]. Dengan kata lain, teks menjadi penghantar makna kultural dalam situasi komunikasi sosial.

Konteks memiliki peran penting dalam penggunaan bahasa, baik konteks situasi maupun konteks budaya. Konteks adalah aspek-aspek internal teks dan segala sesuatu yang secara eksternal melingkupi teks [6]. Menurut sudut pandang konteks, konteks situasi memiliki fungsi utama dalam memahami teks. Dengan memahami situasi pada teks, seseorang dapat memaknai teks dari sudut konteks budaya. Jika konteks budaya dijadikan sudut pandang memaknai teks, maka konteks situasi menjadi pembatas makna. [6] Konteks situasi terjadi karena tiga keadaan, yaitu isi (field), pelibat (participant), dan cara (mode) (Martin dalam Saragih 2006:198). Interaksi sosial melibatkan dua sisi, yakni penutur dan petutur, melibatkan isi yang dituturkan, dan cara penuturannya.

Istilah teks di era revolusi industri ini telah menghibrid menjadi beragam bentuk. Teks tidak hanya berupa tulisan yang dicetak, tetapi teks juga berbentuk multimoda. Teks multimoda memiliki beberapa unsur selain bahasa, yaitu unsur visual berupa gambar diam, gambar bergerak, warna; unsur audio yakni suara, bunyi, music, lagu [7] [8]. Teks multimoda ini pada era 4.0 berevolusi dalam bentuk digital, sehingga istilah yang sering muncul untuk memahami 
teks ini disebut multimoda digital. Maksudnya, teks-teks yang berunsur bahasa, audio, visual yang dapat diakses oleh pengguna secara digital.

Era digital hari ini juga memaksimalkan peran media sosial dalam menjangkau jarak literasi pengguna. Oleh karena itu, teks multimoda hari ini diakses dan disebar dengan mudah melalui aplikasi media sosial seperti Facebook, WhatsApp, Youtube, Instagram, dan Telegram. Aplikasi media sosial ini sangat mempengaruhi teknik berliterasi pengguna. Hal ini juga dapat mempengaruhi tata cara berliterasi pemelajar dan pengajar BIPA. Pemaksimalan media digital melalui sarana media sosial ini akan berdampak besar bagi pembelajaran BIPA, terutama pemelajaran BIPA jarak jauh. Hal inilah yang disebut pengaruh atas bentuk literasi baru, yakni literasi digital yang mengindikasi cara-cara proses literasi membaca, menulis, berbicara, dan menyimak dalam bentuk komunikasi baru [9] [10] [11].

Dalam pembelajaran BIPA, teks menjadi pengantar kegiatan pembelajaran kepada pemelajar. Teks menjadi pintu masuk pembelajaran. Dengan kata lain, pengajar memanfaatkan teks sebagai alat untuk melakukan aktivitas berbahasa yang terkait dengan kehidupan nyata. Pemelajar BIPA belajar berbahasa melalui sajian beragam bentuk teks. Dengan demikian, pembelajaran BIPA dilakukan secara eksplisit yang dikaitkan dengan penggunaan bahasa secara autentik. Pembelajaran aspek kebahasaan selalu dikaitkan dengan karakteristik genre teks sehingga fungsi sosial dan fungsi kulturalnya tergali. Dalam implementasi setiap tahap sintaks dapat menggunakan pendekatan induktif atau deduktif sesuai dengan keperluan dan penekanan. Pembelajaran dilakukan secara integratif yang berfokus pada penguatan kompetensi berbahasa yang didukung penguasaan kompetensi bahasa.

\subsection{Posisi Materi Aspek Kebahasaan Berbasis Teks dalam Permendikbud No 27/2017}

Permendikbud No 27/2017 dapat dijadikan acuan dalam Standar Kompetensi Lulusan (SKL) untuk merumuskan kurikulum, merencanakan bahan pembelajaran, serta menentukan lulusan pemelajar BIPA dalam kursus atau pelatihan. Capaian pembelajaran BIPA dalam Permendikbud No 27/2017 terbagi ke dalam 4 komponen, yakni: (a) sikap dan tata nilai, (b) kemampuan di bidang kerja, (c) pengetahuan yang dikuasai, dan (d) hak dan tanggung jawab. Aspek materi kebahasaan masuk ke dalam komponen pengetahuan yang dikuasai pemelajar BIPA. Terdapat 7 (tujuh) level BIPA untuk sampai pada capaian pembelajaran. Tujuan masing-masing level berfokus pada kompetensi berbahasa secara komunikatif. Misalnya, pada level BIPA 1, capaian lulusan adalah "pemelajar mampu memahami dan menggunakan ungkapan konteks perkenalan diri dan pemenuhan kebutuhan konkret sehari-hari dan rutin dengan cara sederhana untuk berkomunikasi dengan mitra tutur yang sangat kooperatif". Dengan komposisi SKL penguasaan kompetensi kebahasaan di BIPA 1 misalnya "mampu menggunakan kata ganti orang", maka pembelajaran diarahkan pada penguasaan keterampilan berbahasa berbicara yang diintegrasikan dengan keterampilan menyimak dengan tujuan "melatih kemampuan pemelajar dalam komunikasi berbahasa Indonesia pada konteks perkenalan diri” [12].

Dalam konteks pembelajaran BIPA berbasis teks, penguasaan pemelajar terhadap materi kebahasaan perlu diarahkan melalui perantaraan teks. Teks sebagaimana disampaikan di awal, bukan hanya teks satu moda, yaitu teks bermoda bahasa saja, tetapi teks multimoda. Pengajar dapat memilih teks yang diramu dengan unsur moda lain seperti visual (gambar diam atau gambar bergerak), unsur audio (suara, lagu, musik). Pembelajaran bahasa berbasis teks multimoda dilakukan sebagai bagian untuk meningkatkan kompetensi literasi siswa melalui buku teks di Tiongkok [13]; memberikan inspirasi dalam pengajaran sastra [14]; meningkatkan 
kompetensi kesadaran memahami makna semiotik [15]; serta memberdayakan kebermaknaan pembelajaran di kelas bahasa [11].

Melalui Permendikbud No 27/2017 pengajar BIPA penting untuk memahami setiap unit kompetensi, elemen kompetensi, dan indikator lulusan pada aspek "pengetahuan yang dikuasai" untuk setiap level pemelajar. Selain itu, kompetensi pengajar dalam memilih teks yang sesuai dengan level pemelajar dan sesuai dengan aspek kompetensi yang hendak dikuasai menjadi keterampilan mendasar dalam pengajaran BIPA.

\subsection{Skema Model Pembelajaran BIPA Materi Kebahasaan Berbasis Teks}

Pembelajaran BIPA materi Kebahasaan Berbasis Teks Digital 4.0 dimulai dengan membangun konteks. Pada tahap ini, pemelajar diajak untuk membangun pengetahuan berdasarkan konteks pada teks. Pada unit kompetensi (6) yakni "Menguasai penggunaan tata bahasa dan kosa kata dalam berbagai jenis teks yang diajarkan". Serta pada unit capaian kompetensi (6.2) Menguasai pengetahuan tentang penggunaan ganti orang. (6.2.1) Menggunakan kata ganti orang I, II, III (saya, Anda, aku, kamu, ia/dia, nama, kalian, mereka, kami, kita) dengan tepat. Maka, pemelajar disajikan teks percakapan. Teks ini dapat berupa teks video pendek percakapan atau teks chat media sosial. Dengan teknik lain, teks dialog antara pengajar dan pemelajar yang direkam kemudian dibagikan di akun media sosial pengajar dan dilihat oleh pemelajar menjadi teks utama yang disajikan dalam pembelajaran. Membangun konteks teks yang disajikan artinya pengajar mengarahkan pemelajar untuk memahami apa yang disajikan teks; memahami konteks situasi yang disajikan teks; serta memahami konteks budaya yang disajikan teks.

Tahap kedua adalah mendekonstruksi konteks. Pemahaman dekontruksi konteks sendiri artinya menganggap bahwa teks tidak selalu memiliki makna sesuai konteksnya [16] [17]. Artinya, teks memiliki kemampuan penafsiran konteks yang beragam. Makna teks tidak absolut. Dalam pembelajaran BIPA, pemelajar dapat diarahkan untuk melakukan simulasi yang mengembangkan atau mempersempit isi teks yang disajikan di awal. Pemelajar juga dapat diarahkan untuk mensubstitusi teks rumpang pada teks yang disajikan di awal. Misalnya, pada teks "perkenalan diri" yang disajikan dalam bentuk video di media sosial yang telah dibaca pemelajar, pengajar dapat mengganti bentuk teks yang disajikan dengan tampilan yang lebih sederhana pada papan tulis berupa dialog, atau menampilkan teks dalam bentuk kegiatan bermain peran di dalam kelas. Pengajar juga dapat memberikan latihan teks rumpang agar pemelajar dapat mengganti kosa kata rumpang sesuai konteks situasi dan budaya pemelajar.

Tahap ketiga adalah latihan terbimbing. Setelah mendapatkan stimulus berupa kegiatan bermain peran; mengisi teks rumpang, dan sejenisnya, pengajar melatih pemelajar untuk melakukan latihan percakapan. Jika fokus materi kebahasaan adalah "kata ganti", maka pengajar memberikan penguatan kepada pemelajar untuk mempelajari ragam kata ganti bahasa Indonesia. Porsi penguatan materi tidak melampaui latihan berbicara agar kegiatan pembelajaran tetap konsisten pada tujuan kompetensi berkomunikasi. Setelah berlatih, tahap terakhir adalah unjuk kerja mandiri. Pemelajar diarahkan untuk berani tampil mempraktikkan apa yang dipelajarinyta dalam konteks autentik. Misalnya, pemelajar diajak ke tempat umum, seperti perpustakaan untuk memperkenalkan diri dalam bahasa Indonesia. Secara sederhana, skema model pembelajaran BIPA fokus materi kebahasaan berbasis teks digambarkan melalui bagan berikut ini. 


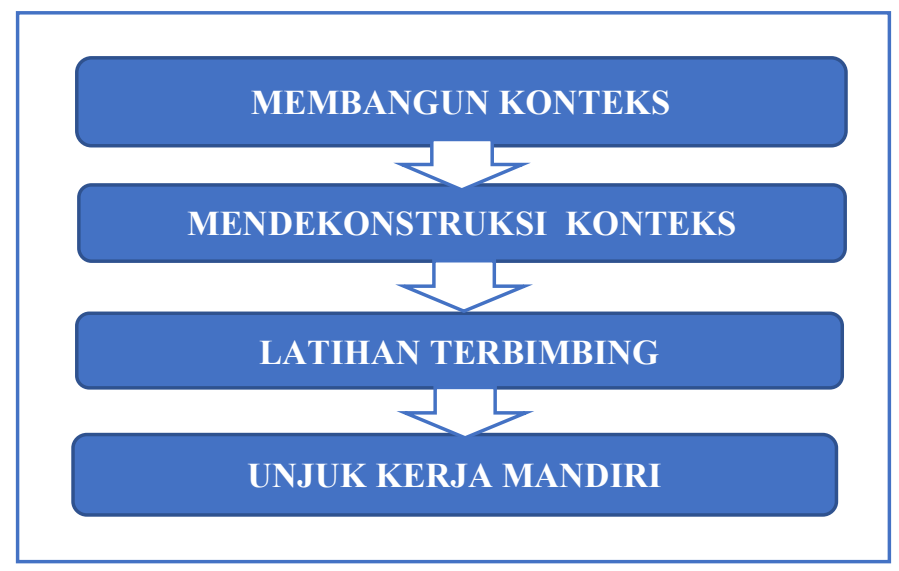

Gambar 1. Skema Model Pembelajaran BIPA Materi Kebahasaan Berbasis Teks

\section{KESIMPULAN}

Era revolusi industri 4.0 memberikan tantangan bagi pengajar BIPA untuk memperkaya bentuk teks bahasa dengan teks multimoda digital dengan memberdayakan jejaring internet. Meski demikian, pembelajaran berbasis teks di era 4.0 tetap harus dilandasi oleh kemampuan dasar pengajar dalam menguasai (1) SKL pembelajaran BIPA yang dapat merujuk pada isi Permedikbud no 27/2017; (2) prinsip-prinsip dasar pembelajaran BIPA; (3) konten disiplin ilmu bahasa Indonesia; (3) berbagai metodologi pembelajaran, khususnya untuk pembelajaran bahasa asing/atau bahasa kedua; konsep pembelajaran andragogi; dan konsep pembuatan perencanaan, pelaksanaan, dan evaluasi pembelajaran.

\section{REFERENCES}

[1] M. R. Ellahia, U. M. Ali Khanb, A. Shaha, "Redesigning Curriculum in line with Industry 4.0," Procedia Computer Science, vol. 151, no. 2019, pp. 699-708, 2019.

[2] A. M. Ivanovic, K. A. Milicevic, V. Aleksic, B. Bratic, M. Mandic, "Experience and perspectives of Technology-enchanged learning and teaching in higher education -Serbian case," Procedia Computer Science, vol. 126, no. 2018, pp. 1351-1359, 2018.

[3] J. S. G. N. \&. Dongme, "On the advantages of computer multimedia aided English teaching," Procedia Computer Science, vol. 131, no. 2018, pp. 727-732, 2018.

[4] P. A. P. Sudana, B. I. D. G. Utama, S. I. M. Paramarta, "Pengembangan media Audio Visual untuk Pembelajaran BIPA (Bahasa Asing bagi Penutur Asing) Tingkat Dasar," in Prosiding Seminar Nasional Riset Inovatif 2017, -, 2017.

[5] M. A. K. Halliday, An Introduction to Functional Grammar, London: Edward Arnold, 1994.

[6] A. Saragih, Bahasa dalam Konteks Sosial, Medan: PPs Unimed, 2006.

[7] V. L. T. Kress, Multimodal Discourse, London: Edward Arnold, 2001. 
[8] J. Murray, Composing multimodality In Lutkewitte C (ed) Multimodal Composition: A Critical Sourcebook, Boston, MA: Bedford/St.Martin's, 2013.

[9] G. Kress \& C. Jewit (Eds.), Multimodal Literacy, New York: Peter Lang, 2003.

[10] K. Pahl \& J. Rowsell, Literacy and Education, Understanding the new Literacy Studies in the Classroom, London: Paul Chapman Publishing, 2005.

[11] M. Walsh, "Worlds Have Collided and Modes Have Merge: Classroom Evidence of Changed Literacy Practices.," Literacy, vol. 42, no. 2, pp. 101-108, 2008.

[12] Permendikbud, "Standar Kompetensi Lulusan Kursus dan Pelatihan Bidang Bahasa Indonesia bagi Penutur Asing". Indonesia Patent 27, - - 2017.

[13] X. Liu \& D. Qu, "Exploring the Multimodality of EFL Textbooks for Chinese College Students: A Comparative Study," RELC Journal, vol. 45, no. 2, pp. 135-150, 2014.

[14] S. Pillai, "Popular Pedagogy: Multimodal Environments for the Teaching and Learning of Literature in the Malaysian Tertiary World," Jurnal Asiatic, vol. 4, no. 2, pp. -, 2010.

[15] A. P. Towndrow, E. M. Nelson, F. W. Mohamed Yusuf, "Squaring Literacy Assessment with Multimodal Design: An Analytic Case for Semiotic Awareness," Journal of Literacy Research, vol. 45, no. 4, pp. 327-355, 2013.

[16] J. Kristeva, Desire in Language: A Semiotic Approach to Language and Art. Trans. Thomas Gora, Alice Jardine and Leon S. Roudiez, ed. Leon S. Roudiez., New York:

[17] Columbia University Press, 1980.

K. Saddhono, Suhartatik, Bagiya, Widodo, and H. Wahyono, "Learning vocabularies using multimedia-based Teaching Indonesian to Speakers of Other Languages (TISOL)," in Journal of Physics: Conference Series, 2019, p. 012108. 